\title{
Surface morphology and deuterium retention in tungsten and tungsten-rhenium alloy exposed to low-energy, high flux D plasma
}

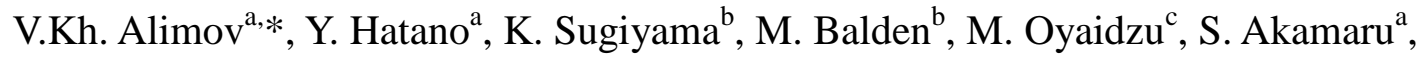 \\ T. Hayashi ${ }^{\text {d }}$ M. Matsuyama ${ }^{\mathrm{a}}$ \\ ${ }^{a}$ Hydrogen Isotope Research Center, University of Toyama, Toyama, 930-8555 Japan, \\ ${ }^{\mathrm{b}}$ Max-Planck-Institut für Plasmaphysik, D-85748 Garching, Germany, \\ ${ }^{\mathrm{c}}$ Tritium Technology Group, Japan Atomic Energy Agency, Rokkasho, Aomori, 039-3212 Japan \\ ${ }^{\mathrm{d}}$ Tritium Technology Group, Japan Atomic Energy Agency, Tokai, Ibaraki, 319-1195, Japan
}

\begin{abstract}
Surface topography and deuterium retention in polycrystalline warm-rolled $\mathrm{W}$ and $\mathrm{W}-5 \% \mathrm{Re}$ have been examined after exposure to a low-energy $\left(76 \mathrm{eV}\right.$ ), high flux (around $10^{22} \mathrm{D} / \mathrm{m}^{2} \mathrm{~s}$ ) deuterium plasma to an ion fluence of $10^{26} \mathrm{D} / \mathrm{m}^{2}$ at various temperatures. The methods used were confocal laser scanning microscopy and the $\mathrm{D}\left({ }^{3} \mathrm{He}, \mathrm{p}\right){ }^{4} \mathrm{He}$ nuclear reaction at ${ }^{3} \mathrm{He}$ energies varied from 0.69 to $4.0 \mathrm{MeV}$. During exposure to the D plasma at temperatures in the range from 348 to $673 \mathrm{~K}$, small blisters of size in the range from about 1 to about $15 \mu \mathrm{m}$, depending on the exposure temperature, are formed on the $\mathrm{W}$ and $\mathrm{W}-5 \% \mathrm{Re}$ surfaces. In the $\mathrm{W}-5 \% \mathrm{Re}$, the deuterium retention demonstrates its maximum at exposure temperature of $463 \mathrm{~K}$, while in the $\mathrm{W}$ this maximum is shifted to $523 \mathrm{~K}$. A difference in the temperature dependence of the $\mathrm{D}$ retention for the $\mathrm{W}$ and $\mathrm{W}-5 \% \mathrm{Re}$ is explained, as a rough approximation, by temperature dependences of the ductility of these materials.
\end{abstract}

*Corresponding author. Tel.: +81 76445 6934; fax: +81 764456931.

E-mail address: vkahome@mail.ru (V.Kh. Alimov). 


\section{Introduction}

Due to its favorable physical properties, such as low erosion yield and high melting temperature, tungsten (W) is employed as a candidate material for plasma-facing high heatflux structures in future fusion reactors. As plasma-facing material in fusion reactors, W will be subject to intensive fluxes of energetic deuterium (D) and tritium (T) particles, as well as $14 \mathrm{MeV}$ neutrons (n) from the D-T fusion reaction. Neutron irradiation generates displacements in the bulk of $\mathrm{W}$ and creates thus defects at which hydrogen isotopes can be trapped. Furthermore, irradiation of $\mathrm{W}$ with fusion neutrons creates several radioactive isotopes of tungsten and rhenium $(\mathrm{Re})$. There has been a number of studies trying to predict the amount of Re accumulated in $\mathrm{W}$ during fusion power plant operation [1-4]. The most recent forecast by Gilbert and Sublet [4] gives 0.18 at.\% of Re for 14 years of ITER operation and 3.8 at.\% of Re for 5 years of DEMO operation.

Not much is known about the influence of Re addition on hydrogen isotope inventory in W-based materials. Golubeva et al. [5] reported that after irradiation with $200 \mathrm{eV}$ D ions at $300 \mathrm{~K}$, deuterium retention in $\mathrm{W}$-Re alloys was higher that than in polycrystalline $\mathrm{W}$. In a study by Tyburska-Püschel and Alimov [6], W and W-3\%Re samples were initially damaged by irradiation with $20 \mathrm{MeV} \mathrm{W}$ ions to simulate $n$-induced displacement damage and then were exposed to low-energy (76 eV/ion), high flux $\left(\approx 10^{22} \mathrm{D} / \mathrm{m}^{2} \mathrm{~s}\right)$ D plasma at various temperatures. Results obtained showed that at exposure temperatures above $450 \mathrm{~K}$ the concentration of deuterium trapped at W-ion-induced defects in W-3\%Re alloy is significantly lower than that in pure W. However, there are no results on hydrogen retention in undamaged W-Re materials exposed to high flux hydrogen plasmas.

Available data ([7] and references therein) show that hydrogen isotope retention in $\mathrm{W}$ materials exposed to low-energy ${ }^{1}$, high flux hydrogen plasmas differs from that for lowenergy ion implantation. For W materials exposed to low-energy, high flux hydrogen plasmas, local plastic deformation caused by hydrogen super-saturation within the nearsurface layer [8] is suggested as a mechanism for formation of intergranular and intragranular cracks, and, at long-term plasma exposure, for gas-filled void formation at depths up to several micrometers and, as consequence, for blistering [9-11]. It is known that an addition of Re not only improves the low temperature ductility of the tungsten material, but also increases

\footnotetext{
${ }^{1}$ The term 'low-energy ions' means that the ion energy is below the displacement threshold.
} 
its high temperature creep strength ${ }^{2}$ [12-14]. Thus, it's possible to suppose that a change of the $\mathrm{W}$ mechanical properties can affect the hydrogen retention. The objective of this work is to perform a comparative study of surface morphology and D retention in W and W-Re alloy exposed to high flux D plasma.

\section{Experimental}

Two W-based materials were used in this work: (i) $1 \mathrm{~mm}$ thick warm-rolled $\mathrm{W}$ plate of 99.95 wt.\% purity from Goodfellow Cambridge Ltd, England, and (ii) $1 \mathrm{~mm}$ thick warmrolled W-5\%Re alloy plate of 99.99 wt.\% purity delivered by A.L.M.T. Corp., Japan. After cutting of the plates into samples $10 \times 10 \mathrm{~mm}^{2}$ in size, the samples were mechanically polished, cleaned in an acetone ultrasonic bath, and annealed in vacuum at $1223 \mathrm{~K}$ for $1 \mathrm{~h}$ to relieve stresses occurred in the polishing process.

The cross-sections of the samples were examined by scanning electron microscopy (SEM) combined with focused ion beam cross-sectioning (FIB) (FEI, Helios NanoLab 600). According to cross-section images obtained by SEM/FIB, the microstructure of the warmrolled $\mathrm{W}$ and $\mathrm{W}-5 \%$ Re consists of two-dimensional flat (sub-)grains ${ }^{3}$, up to $5 \mu \mathrm{m}$ in size and up to $1 \mu \mathrm{m}$ in thickness, elongated in parallel to the surface (Fig. 1).

The $\mathrm{W}$ and $\mathrm{W}-5 \%$ Re samples were exposed to low-energy, high ion flux deuterium plasma in the linear plasma generator described in Ref. [15]. To generate high flux D plasma, the $\mathrm{D}_{2}$ working pressure was kept at about $1 \mathrm{~Pa}$. As a result, a plasma beam with species of $\mathrm{D}_{2}{ }^{+}$(about $80 \%$ ) and $\mathrm{D}^{+}$(about 20\%) was obtained. A bias voltage of $-80 \mathrm{~V}$ was applied to the sample, resulting in incident ion energy of $76 \mathrm{eV}$, taking into account the plasma potential of about $-4 \mathrm{~V}$ as measured by a Langmuir probe. The incident ion flux was in the range of $(1.0 \div 1.4) \times 10^{22} \mathrm{D} / \mathrm{m}^{2} \mathrm{~s}$, whereas the ion fluence was fixed at $10^{26} \mathrm{D} / \mathrm{m}^{2}$, i.e., the ion charge was recorded and the exposure was stopped after reaching $10^{26} \mathrm{D} / \mathrm{m}^{2}$. The exposure temperature was set by the thermal contact between the sample and the cooled holder, and the temperature

\footnotetext{
${ }^{2}$ Ductility is a mechanical property that describes the extent in which solid materials can be plastically deformed without fracture. Creep strength is the pressure at which a given deformation is achieved in a given time.

${ }^{3}$ For subgrains with small $\left(<<1^{\circ}\right)$ misorientation, the grain orientation contrast is sufficient to be visible in the SEM images.
} 
was monitored using a type $\mathrm{K}$ thermocouple tightly pressing to the rear of the sample. The samples were exposed at five temperatures in the range from 348 to $673 \mathrm{~K}$.

The $\mathrm{D}$ concentration within the near-surface layer (at depths up to about $0.5 \mu \mathrm{m}$ ) was measured by means of the $\mathrm{D}\left({ }^{3} \mathrm{He}, \alpha\right) \mathrm{H}$ reaction at a ${ }^{3} \mathrm{He}$ energy of $0.69 \mathrm{MeV}$ with total ${ }^{3} \mathrm{He}$ ion charge of $10 \mu \mathrm{C}$ acquired on a spot size of $1 \mathrm{~mm}^{2}$. The $\alpha$ particles were energy-analyzed with a small-angle surface barrier detector at the laboratory scattering angle of $102^{\circ}$. The $\alpha$ spectrum was transformed into a D depth profile using the program SIMNRA [16].

To determine the $\mathrm{D}$ concentration at greater depths, an analyzing beam of ${ }^{3} \mathrm{He}$ ions with energies varied from 0.69 to $4.0 \mathrm{MeV}$ was used, and at these energies the total ${ }^{3} \mathrm{He}$ ion charge was $5 \mu \mathrm{C}$. The protons from the $\mathrm{D}\left({ }^{3} \mathrm{He}, \mathrm{p}\right)^{4} \mathrm{He}$ nuclear reaction were counted using a wideangle detector placed at a scattered angle of $135^{\circ}$, and the program SIMNRA was used for the deconvolution of the measured proton yields. The $\mathrm{D}$ depth distribution was established by a sequence of layers with thicknesses equivalent to the depth resolution of the method ranging from $10^{17} \mathrm{~W} / \mathrm{cm}^{2}$ at the surface to $10^{19} \mathrm{~W} / \mathrm{cm}^{2}$ at a depth of $7 \mu \mathrm{m}$ as calculated using the code RESOLNRA [17]. A concentration of deuterium as a function of depth was assumed taking into account the near-surface D concentration profile obtained from the $\alpha$ particle spectrum, and the proton counts resulting from the assumed D depth profile was calculated for the different ${ }^{3} \mathrm{He}$ ion energies. The assumed D depth profile was iteratively adjusted until the calculated proton yield curve matched the experimentally measured proton yield data set [18]. The amount of D retained at depths of up to $7 \mu \mathrm{m}$ was obtained from the sum of the D content in the layers.

Total deuterium retention in the $\mathrm{W}$ samples was monitored ex-situ using thermal desorption spectrometry (TDS). A ceramic heater was used to heat the samples at a ramp rate of $0.5 \mathrm{~K} / \mathrm{s}$ and the sample temperature was raised to $1173 \mathrm{~K}$. HD, and $\mathrm{D}_{2}$ molecules released during the TDS run were monitored by a quadrupole mass spectrometer (QMS). To calculate the relative contribution of the recorded HD and $\mathrm{D}_{2}$ masses to the total release of deuterium, the partial currents of the QMS were normalized as described in Ref. [19]. A standard $\mathrm{D}_{2}$ leak with an inaccuracy smaller than $10 \%$ was employed to calibrate the QMS.

The surface morphology of the plasma-exposed samples was analyzed with a confocal laser scanning microscope (CLSM).

\section{Results}




\subsection{Surface morphology}

After D plasma exposures at all temperatures utilized in this study, micrometer-sized blisters are observed on the $\mathrm{W}$ and $\mathrm{W}-5 \% \mathrm{Re}$ surfaces. On the $\mathrm{W}[348 \mathrm{~K}]^{4}$ and $\mathrm{W}$ $5 \% \operatorname{Re}[353 \mathrm{~K}]$ surfaces, the blister density is about the same, while the density of $5-8 \mu \mathrm{m}$ sized blisters is observed to be slightly higher on the W [348 K] surface (Fig. 2 (a, b)).

As the exposure temperature increases to $453-463 \mathrm{~K}$, maximum size of blisters grows and reaches $12-15 \mu \mathrm{m}$ both on the $\mathrm{W}$ and $\mathrm{W}-5 \%$ Re surfaces. However, the density of small-sized $(1-5 \mu \mathrm{m})$ blisters on the $\mathrm{W}-5 \% \operatorname{Re}[463 \mathrm{~K}]$ surface is higher than that on the $\mathrm{W}[453 \mathrm{~K}]$ surface (Fig. $2($ d, e)).

After exposures at $T_{\text {exp }}=523 \mathrm{~K}$, CLSM images demonstrate well-defined distinction in blistering on the $\mathrm{W}$ and $\mathrm{W}-5 \% \mathrm{Re}$ surfaces. On the $\mathrm{W}[523 \mathrm{~K}]$ surface the blister density is higher and the maximum blister size (about $20 \mu \mathrm{m}$ ) is larger than those on the W$5 \% \operatorname{Re}[523 \mathrm{~K}]$ surface (Fig. $2(\mathrm{e}, \mathrm{f}))$.

At $T_{\exp }=583$ and $673 \mathrm{~K}$, only small-sized blisters are observed both on the $\mathrm{W}$ and $\mathrm{W}$ $5 \% \operatorname{Re}$ surfaces (images are not shown).

\subsection{Deuterium depth profiles}

In the $\mathrm{W}$ and $\mathrm{W}-5 \% \mathrm{Re}$ samples exposed to the $\mathrm{D}$ plasma at $T_{\exp }=348-353 \mathrm{~K}$, deuterium depth profiles are characterized by a sharp near-surface concentration maximum of 5-10 at.\%. At depths from 0.1 to $3 \mu \mathrm{m}$, the D concentration in these samples decreases from $0.5-0.7$ at.\% to about $10^{-2}$ at. $\%$. At greater depths, up to $7 \mu \mathrm{m}$, the $\mathrm{D}$ concentration is practically constant and equals to $(2-4) \times 10^{-3}$ at.\% (Fig. 3). From the results obtained it may be deduced that in the case of high flux D plasma exposure, the $\mathrm{W}[348 \mathrm{~K}]$ and $\mathrm{W}-5 \% \operatorname{Re}[353]$ samples show the same hydrogen retention properties.

As the temperature $T_{\exp }$ increases to $453-463 \mathrm{~K}$, the $\mathrm{D}$ concentration in the $\mathrm{W}$ and $\mathrm{W}$ $5 \%$ Re near-surface layers decreases by a factor of 3-5 as compared with that for $T_{\exp }=348$ $353 \mathrm{~K}$. As this takes place, in the $\mathrm{W}[453 \mathrm{~K}]$ sample the D concentration decreases by a factor of about two across the whole analyzing depth as compared with that for the $\mathrm{W}$ [348 $\mathrm{K}]$ sample. In its turn, in the $\mathrm{W}-5 \% \operatorname{Re}[463 \mathrm{~K}]$ sample the D concentration at depths from 1 to 3 $\mu \mathrm{m}$ increases significantly as compared with that in the $\mathrm{W}-5 \% \operatorname{Re}[353 \mathrm{~K}]$ sample (Fig. 3).

\footnotetext{
${ }^{4}$ For the sake of convenience, the exposure temperature, $T_{\text {exp }}$, for each sample is indicated in brackets.
} 
After exposure of the $\mathrm{W}$ sample to the D plasma at $T_{\exp }=523 \mathrm{~K}$, the $\mathrm{D}$ concentration in the near surface layer and bulk (up to $5 \mu \mathrm{m}$ ) increases slightly as compared with that for $T_{\exp }$ $=453 \mathrm{~K}$. By contrast, in the $\mathrm{W}-5 \% \operatorname{Re}[523 \mathrm{~K}]$ sample, the D concentration decreases by more than one order of magnitude across the whole analyzing depth as compared with that for the W-5\%Re [463 K] sample (Fig. 3).

Further increase of the exposure temperature leads to a decrease in the D concentration in the $\mathrm{W}$ and $\mathrm{W}-5 \% \operatorname{Re}$ samples. Note that the D concentration in the $\mathrm{W}-5 \% \operatorname{Re}[583 \mathrm{~K}]$ sample is significantly lower than that in the $\mathrm{W}[583 \mathrm{~K}]$ sample. However, at $T_{\exp }=673 \mathrm{~K}$, the D depths profiles in these both materials are comparable and are described by a near-surface concentration maximum of about 0.1 at.\% (Fig. 3).

\subsection{Deuterium retention}

For the $\mathrm{W}$ and $\mathrm{W}-5 \% \mathrm{Re}$ samples, temperature dependences of the total $\mathrm{D}$ retention, as determined by TDS, and the D retention up to a depth of $7 \mu \mathrm{m}$ (the sub-surface $\mathrm{D}$ retention), as measured by NRA, are shown in Fig. 4 (a). After D plasma exposure at $T_{\exp }=348-353 \mathrm{~K}$, the $\mathrm{D}$ retention values for these samples are practically the same. However, the retention in the W-5\%Re [463 K] sample increases and becomes significantly higher than that in the $\mathrm{W}[453 \mathrm{~K}]$. Obviously, in the $\mathrm{W}-5 \%$ Re sample the $\mathrm{D}$ retention values have maxima at $T_{\exp }$ of around $463 \mathrm{~K}$, since at higher exposure temperatures the retention value starts to decrease. In its turn, the $\mathrm{D}$ retention values in the $\mathrm{W}$ sample demonstrate maxima at $T_{\exp }=523 \mathrm{~K}$. At exposure temperature of $673 \mathrm{~K}$, the total retention values for both materials to be investigated are around $10^{19} \mathrm{D} / \mathrm{m}^{2}$ (Fig. 4 (a)).

\section{Discussion}

As already noted, for tungsten exposed to low-energy, high flux hydrogen plasmas, plastic deformation caused by hydrogen atom supersaturation [8] is considered to generate defects responsible for accumulation of the implanted hydrogen [10]. During exposure to the high flux hydrogen plasma, a high hydrogen concentration in the implantation zone stresses the matrix lattice. When the compressive stress induced by the hydrogen supersaturation exceeds the yield stress of the material, fracture deformation and/or plastic deformation occur [8], and both intergranular/intragranular cracks (cavities) [10] and vacancy-type defects (vacancies and vacancy clusters) [20] are generated. Diffusing hydrogen atoms are trapped at the 
vacancy-type defects forming consequently gas bubble nuclei, and recombine also on the cavity surfaces. High hydrogen fugacity maintained during the plasma exposure increases gas pressure both in the cavities and bubbles. As this takes place, the bubbles expand by dislocation loop punching [21]. The growing bubbles can be interconnected forming thereby new cavities [22]. As reported in Ref. [11], high gas pressure in the cavities (several tenth of $\mathrm{GPa}$ ) is causal for formation of elastically or/and plastically deformed blisters on the surface of polycrystalline $\mathrm{W}$, depending on the exposure conditions.

Based on the belief that $\mathrm{D}$ retention in $\mathrm{W}$ and $\mathrm{W}-\mathrm{Re}$ materials is dictated by formation of stress-induced defects, a difference in the temperature dependences of the D retention in $\mathrm{W}$ and W-5\%Re samples (Fig. 4 (a)) can be explained by temperature dependences of ductility of these materials, as a rough approximation. It should be noted that the hydrogen isotope permeabilities for polycrystalline $\mathrm{W}$ and $\mathrm{W}-5 \%$ Re materials are close in values [23].

At room temperature, tungsten generally fails by low-energy brittle cleavage; above a critical brittle-to-ductile transition (BDT) temperature, $T_{\mathrm{BDT}}$, the fracture mode may be ductile, with a greater or lesser amount of crack-tip or macroscopic plastic deformation [24]. For polycrystalline $\mathrm{W}$, the BDT temperature is shifted from 390 to $500 \mathrm{~K}$ as strain rate increases from $4 \times 10^{-5}$ to $5 \times 10^{-2} / \mathrm{s}$ [24]. The BDT temperature depends also on the material microstructure and, for $\mathrm{W}$ single crystals, on the crystal-lattice orientation [25]. Note that in $\mathrm{W}$ materials liable to plastic deformation under D plasma exposure, vacancy-type defects are produced in very high densities which are typically close to those of vacancies in thermal equilibrium at the melting point [20], and the vacancy-type defects are formed in surroundings of D atoms.

There are no data on the BDT temperatures for warm-rolled $\mathrm{W}$ and $\mathrm{W}-5 \%$ Re samples subjected to high-flux D plasma exposures. As illustrated for the example of recrystallized W exposed to low-energy, high flux D plasma [10], at exposure temperatures above the BDT temperature the dislocation mobility is increased and the stress can be relaxed by dislocations moving along lattice planes through the whole crystallite leading to formation of cavities at the grain boundaries at depths of several tens of micrometers. This corresponds to the material migration above the surface, i.e., the blister-like surface topography. As this takes place, the D retention increases significantly [10]. Based on the temperature dependence of blister formation and D retention in recrystallized W exposed to low-energy, high flux D plasma with the same ion composition, ion energy and ion flux as used in this work [26], the BDT temperature for the plasma-exposed recrystallized $\mathrm{W}$ can be speculated to lie between 460 
and $500 \mathrm{~K}$. According to the strain rate dependence of the BDT temperature for recrystallized and polycrystalline $\mathrm{W}[24,27]$, the BDT temperatures for these materials are practically equal. Thus, it is believed that the brittle-to-ductile transition in the plasma-exposed warmrolled $\mathrm{W}$ occurs at a temperature between 460 and $500 \mathrm{~K}$.

It is known that the ductility of W-Re alloys differs from that for pure $\mathrm{W}[13,14,28,29]$. As reported in Ref. [14], the BDT temperature for W-Re alloys, $T_{\mathrm{BDT}}(\mathrm{W}-\mathrm{Re})$, is lower than the BDT temperature for $\mathrm{W}, T_{\mathrm{BDT}}(\mathrm{W})$, i.e., $T_{\mathrm{BDT}}(\mathrm{W}-\mathrm{Re})<T_{\mathrm{BDT}}(\mathrm{W})($ Fig. $4(\mathrm{~b})$ ). At temperatures below $T_{\mathrm{BDT}}(\mathrm{W}-\mathrm{Re})$, brittle fracture in these materials occurs at stress levels consistent with the level for macroscopic yielding. At temperatures in the range from $T_{\mathrm{BDT}}(\mathrm{W}-\mathrm{Re})$ to $T_{\mathrm{BDT}}(\mathrm{W})$, $\mathrm{W}$-Re alloys are already ductile while $\mathrm{W}$ demonstrates brittle properties. At temperatures above $T_{\mathrm{BDT}}(\mathrm{W})$, the ductility of W-Re alloys is lower than the ductility of W (Fig. 4 (b)).

At $T_{\exp }=348-353 \mathrm{~K}$, the mechanical properties of the warm-rolled $\mathrm{W}$ and $\mathrm{W}-5 \% \mathrm{Re}$ samples are thought to be practically identical, and amounts of stress-induced defects, mainly cracks, responsible for $\mathrm{D}$ accumulation in both materials are comparable. As this takes place, the $\mathrm{D}$ retention in the $\mathrm{W}[348 \mathrm{~K}]$ sample is close to that for the $\mathrm{W}-5 \% \operatorname{Re}[353 \mathrm{~K}]$ sample (Fig. 4 (a)).

At higher exposure temperatures, the $\mathrm{W}-5 \% \operatorname{Re}[463 \mathrm{~K}]$ sample is ductile, whereas the $\mathrm{W}$ [453 K] sample is brittle (Fig. 4 (b)), and the amount of D retained in the W-5\% Re [463 K] sample is higher than the D content in the W [453 K] sample (Fig. 4 (a)). High density of small-sized blisters on the W-5\%Re [463 K] surface (Fig. 2 (d and e)) suggests that a major portion of retained deuterium is contained in small gas-filled cavities associated with these blisters.

At $T_{\exp } \geq 523 \mathrm{~K}$ the ductility of the $\mathrm{W}-5 \%$ Re samples is lower than that for the $\mathrm{W}$ samples (Fig. 4 (b)), and the D content in the W-5\%Re samples become lower than in the W samples (Fig. 4 (a)).

Therefore, the higher is ductility of the W-based material, the larger is the amount of D retained at stress-induced defects. During exposure to low-energy, high flux D plasma, deuterium is accumulated both in pressurized cavities visible as blisters $[10,11]$ and invisible vacancy-type defects and gas bubbles [21, 30]. It may be suggested that in the brittle $\mathrm{W}[348 \mathrm{~K}], \mathrm{W}-5 \% \operatorname{Re}[353 \mathrm{~K}]$, and $\mathrm{W}[453 \mathrm{~K}]$ samples formation of the gas-filled cracks dominates in the $\mathrm{D}$ retention. However, in the ductile $\mathrm{W}-5 \% \operatorname{Re}[463 \mathrm{~K}]$ sample additional generation of the vacancy-type defects and high dense gas bubbles significantly increases the D content as compared to that for W [453 K] sample (Fig. 4 (a)). At exposure temperatures in the range from 523 to $683 \mathrm{~K}$, the fraction of $\mathrm{D}$ retained in the gas bubbles and cavities in the 
ductile $\mathrm{W}$ and $\mathrm{W}-5 \%$ Re samples is thought to increase with ductility of the material. As this takes place, at the same D plasma exposure conditions, the D retention in the $\mathrm{W}$ samples is higher than that in the W-5\%Re samples (Fig. 4 (a)).

\section{Summary}

Moderate temperature dependence of surface morphology is found for warm-rolled W and $\mathrm{W}-5 \%$ Re exposed to low-energy $\left(76 \mathrm{eV}\right.$ ), high-flux (about $10^{22} \mathrm{D} / \mathrm{m}^{2} \mathrm{~s}$ ) D plasma at an ion fluence of $10^{26} \mathrm{D} / \mathrm{m}^{2}$. During D plasma exposures at temperatures in the range from 348 to $673 \mathrm{~K}$, blisters of size in the range from 1 to $20 \mu \mathrm{m}$ are formed on the $\mathrm{W}$ and $\mathrm{W}-5 \% \mathrm{Re}$ surfaces. Size and density of blisters on the W surface increase with temperature up to $523 \mathrm{~K}$ but turn to decrease above $583 \mathrm{~K}$. On the other hand, on the $\mathrm{W}-5 \% \mathrm{Re}$ surface the transition temperature of this blistering behavior shifts to lower temperature, i.e. blisters starts to decrease already at $523 \mathrm{~K}$.

The temperature dependences of the $\mathrm{D}$ retention in the $\mathrm{W}$ and $\mathrm{W}-5 \%$ Re materials diverge in temperatures where the retention reach its maximum $(463 \mathrm{~K}$ for $\mathrm{W}-5 \% \mathrm{Re}$ and about $523 \mathrm{~K}$ for $\mathrm{W}$ ), which is consistent with the blistering characteristics on the $\mathrm{W}$ and $\mathrm{W}-5 \% \mathrm{Re}$ surfaces. This different temperature behavior of the $\mathrm{D}$ retention is explained, as a rough approximation, by temperature dependences of ductility of $\mathrm{W}$ and $\mathrm{W}-5 \% \mathrm{Re}$.

\section{Acknowledgements}

The authors would like to thank G. Matern (IPP Garching, Germany) for preparation and metallographic images of the $\mathrm{W}$ and $\mathrm{W}-5 \%$ Re samples, and J. Dorner and M. Fußeder (IPP Garching, Germany) for technical assistance with the ${ }^{3} \mathrm{He}$ beam analyses. This work was partly supported by the NIFS Collaboration Research Program (NIFS13KUMR013) and the Japan Atomic Energy Agency as a part of Broader Approach Activities (\#25K286). 


\section{References}

[1] T. Noda, M. Fujita, M. Okada, J. Nucl. Mater. 258-263 (1998) 934.

[2] G.A. Cottrell, J. Nucl. Mater. 334 (2004) 166.

[3] G.A. Cottrell, R. Pampin, N.P. Taylor, Fusion Sci. Technol. 50 (2006) 89.

[4] M.R. Gilbert and J.-Ch. Sublet, Nucl. Fusion 51 (2011) 043005.

[5] A.V. Golubeva, M. Mayer, J. Roth, V.A. Kurnaev, O.V. Ogorodnikova, J. Nucl. Mater. 363-365 (2007) 893.

[6] B. Tyburska-Püschel and V.Kh. Alimov, Nucl. Fusion 53 (2013) 123021.

[7] C.H. Skinner, A.A. Haasz, V.Kh. Alimov, N. Bekris, R.A. Causey, R.E.H. Clark, J.P. Coad, J.W. Davis, R.P. Doerner, M. Mayer, A. Pisarev, J. Roth, T. Tanabe, Fusion Sci. Technol. 54 (2008) 891.

[8] J.B. Condon and T. Schober, J. Nucl. Mater. 207 (1993) 1.

[9] A.A. Haasz, M. Poon, J. Davis, J. Nucl. Mater. 266-269 (1999) 520.

[10] S. Lindig, M. Balden, V.Kh. Alimov, T. Yamanishi, W.M. Shu, J. Roth, Phys. Scr. T138 (2009) 014040.

[11] M. Balden, S. Lindig, A. Manhard, J.-H. You, J. Nucl. Mater. 414 (2011) 69.

[12] H.P. Gao and R.H. Zee, J. Mater. Sci. Lett. 20 (2001) 885.

[13] P. Makarov and K. Povarova, Int. J. Refract. Metals Hard Mater. 20 (2002) 277.

[14] P.L. Raffo, Yielding and Fractures in Tungsten and Tungsten-Rhenium Alloys, NASA Technical Note D-4567, National Aeronautics and Space Administration, Washington, D.C., 1968.

[15] G.-N. Luo, W.M. Shu, H. Nakamura, S. O’Hira, M. Nishi, Rev. Sci. Instrum. 75 (2004) 4374.

[16] M. Mayer, SIMNRA User's Guide, Tech. Rep. IPP 9/113, Max-Planck-Institut für Plasmaphysik, Garching, 1997.

[17] M. Mayer, Nucl. Instr. Meth. B 266 (2008) 1852.

[18] V.Kh. Alimov, M. Mayer, J. Roth, Nucl. Instr. Meth. B 234 (2005) 169.

[19] P. Franzen, B.M.U. Scherzer, W. Möller, Nucl. Instr. Meth. B 67 (1992) 536.

[20] M.J. Zehetbauer, G. Steiner, E. Schafler, A.V. Korznikov, E. Korznikova, Mater. Sci. Forum 503-504 (2006) 57.

[21] R.D. Kolasinski, D.F. Cowgill, R.A. Causey, J. Nucl. Mater. 415 (2011) S676. 
[22] Y. Ueda, T. Funabiki, T. Shimada, K. Fukumoto, H. Kurishita, M. Nishikawa, J. Nucl. Mater. 337-339 (2005) 1010.

[23] G. Benamati, E. Serra, C.H. Wu, J. Nucl. Mater. 283-287 (2000) 1033.

[24] A. Giannattasio and S.G. Roberts, Phil. Mag. 87 (2007) 2589.

[25] P. Gumbsch, J. Riedle, A. Hartmaier, H. F. Fischmeister, Science 282 (1998) 1293.

[26] V.Kh. Alimov, B. Tyburska-Püschel, S. Lindig, Y. Hatano, M. Balden, J. Roth, K. Isobe, M. Matsuyama, T. Yamanishi, J. Nucl. Mater. 420 (2012) 519.

[27] A. Giannattasio, Z. Yao, E. Tarleton, S.G. Roberts, Phil. Mag. 90 (2010) 3947.

[28] Y. Mutoh, K. Ichikawa, K. Nagata, M. Takeuchi, J. Mater. Sci. 30 (1995) 770.

[29] S. Wurster, N. Baluc, M. Battabyal, T. Crosby, J. Du, C. García-Rosales, A. Hasegawa, A. Hoffmann, A. Kimura, H. Kurishita, R.J. Kurtz, H. Li, S. Noh, J. Reiser, J. Riesch, M. Rieth, W. Setyawan, M. Walter, J.-H. You, R. Pippan, J. Nucl. Mater. 442 (2013) S181.

[30] R.D. Kolasinski, D.F. Cowgill, D.C. Donovan, M. Shimada, W.R. Wampler, J. Nucl. Mater. 438 (2013) S1019. 


\section{Figure captures}

Figure 1. SEM/FIB cross section images of warm-rolled $\mathrm{W}$ and $\mathrm{W}-5 \%$ Re (tilted by $38^{\circ}$ )

Figure 2. CLSM images of warm-rolled W (a, c, e - left part of the figure) and W-5\% Re (b, d, $\mathrm{f}$ - right part of the figure) exposed to low-energy, high flux D plasma with an ion fluence of $10^{26} \mathrm{D} / \mathrm{m}^{2}$ at indicated temperatures. The scale bar given in panel (f) is valid for all images.

Figure 3. Depth profiles of deuterium retained in warm-rolled W (a) and $\mathrm{W}-5 \% \mathrm{Re}$ (b) exposed to low-energy, high flux D plasma with an ion fluence of $10^{26} \mathrm{D} / \mathrm{m}^{2}$ at various temperatures. The vertical lines show the nine layers used for the SIMNRA calculations. For each layer, the D concentration is constant across the whole layer width.

Figure 4. (a) Deuterium retention of warm-rolled W and W-5\%Re exposed to low-energy, high flux D plasma with an ion fluence of $10^{26} \mathrm{D} / \mathrm{m}^{2}$, as a function of the exposure temperature. The total deuterium retention was determined by thermal desorption spectrometry (TDS) (half-filled symbols), whereas the D retention up to a depth of $7 \mu \mathrm{m}$ was measured by nuclear reaction analysis (NRA) (open symbols). (b) Effect of rhenium on ductility of arc-melted tungsten determined by tensile tests at a strain rate of approximately $8 \times 10^{-4} / \mathrm{s}[14]$. 


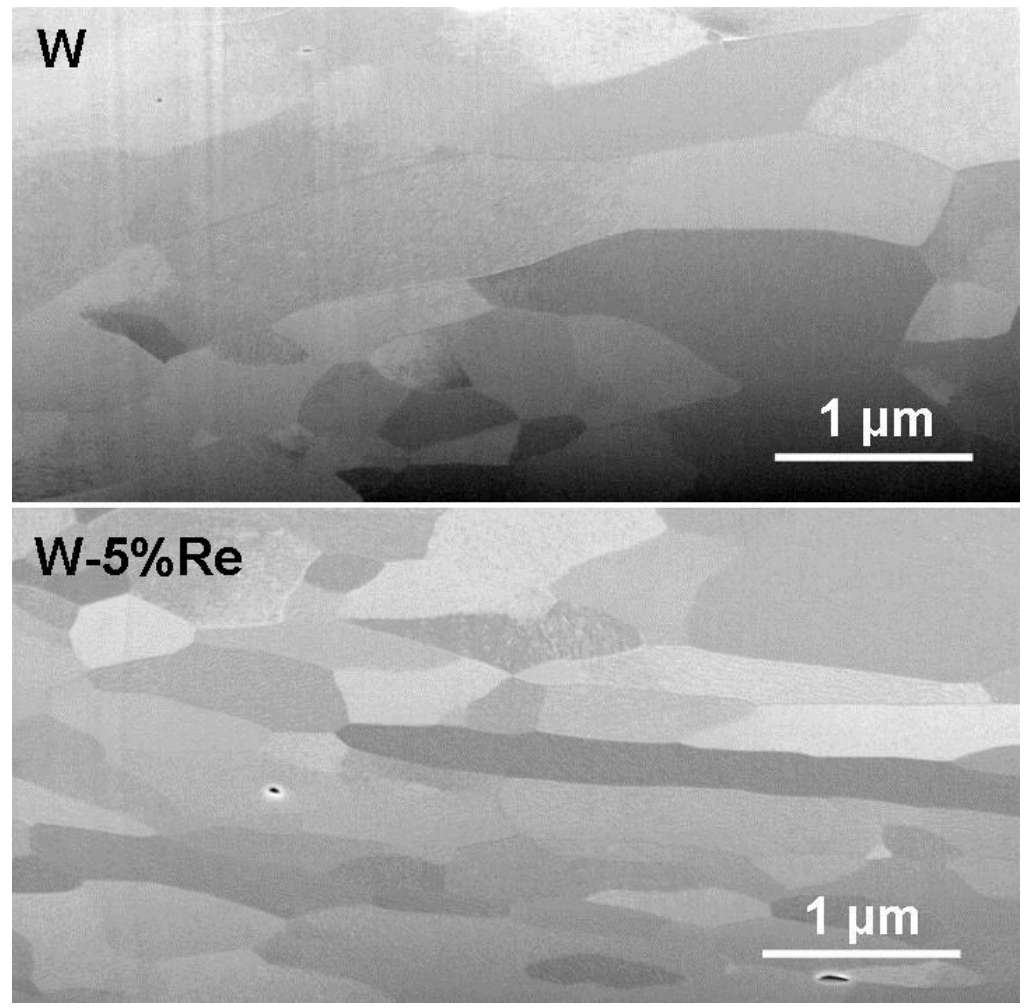

Figure 1. SEM/FIB cross section images of warm-rolled $\mathrm{W}$ and $\mathrm{W}-5 \%$ Re (tilted by $38^{\circ}$ ) 


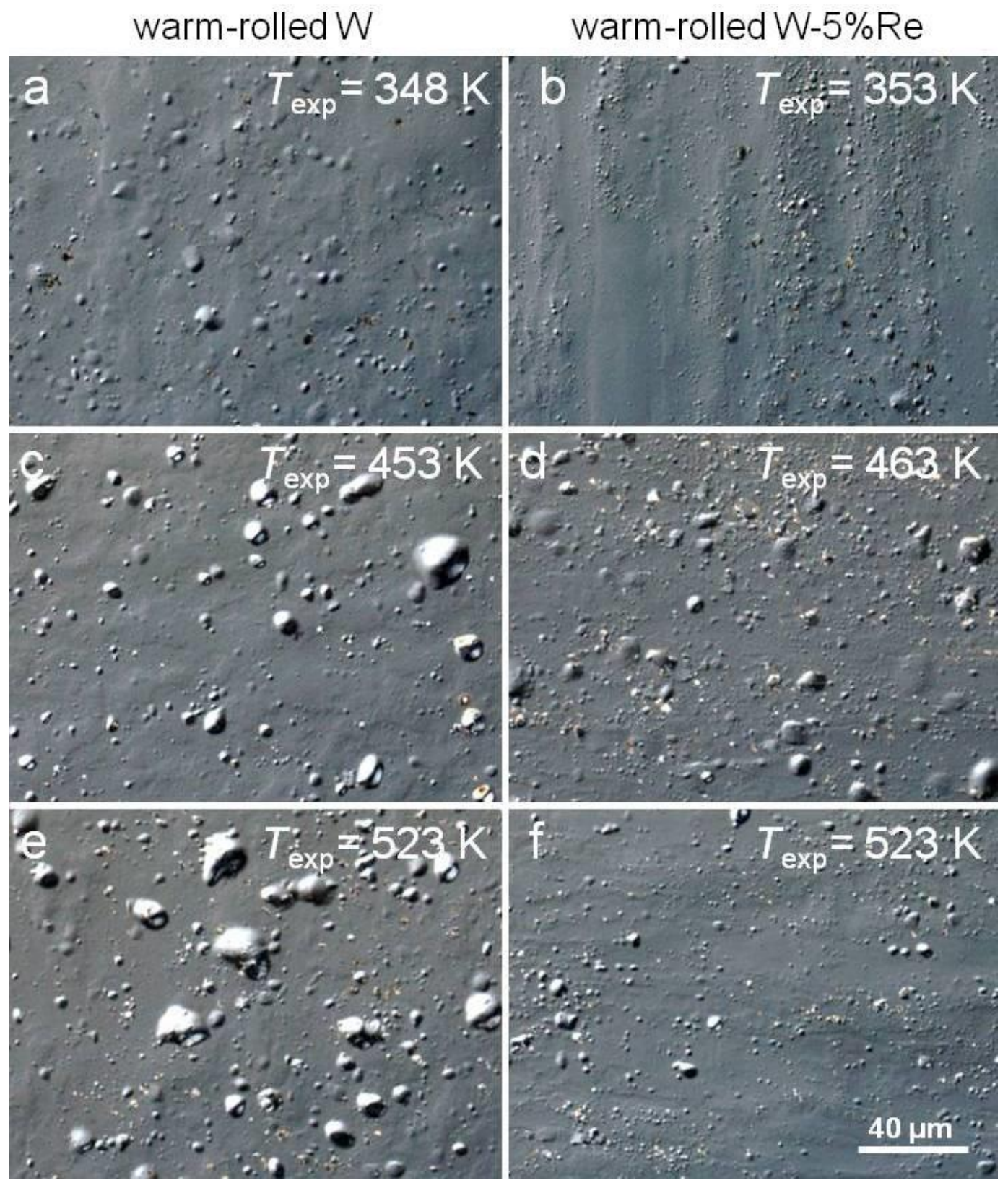

Figure 2. CLSM images of warm-rolled W (a, c, e - left part of the figure) and W-5\%Re (b, d, $\mathrm{f}$ - right part of the figure) exposed to low-energy, high flux D plasma with an ion fluence of $10^{26} \mathrm{D} / \mathrm{m}^{2}$ at indicated temperatures. The scale bar given in panel ( $\mathrm{f}$ ) is valid for all images. 


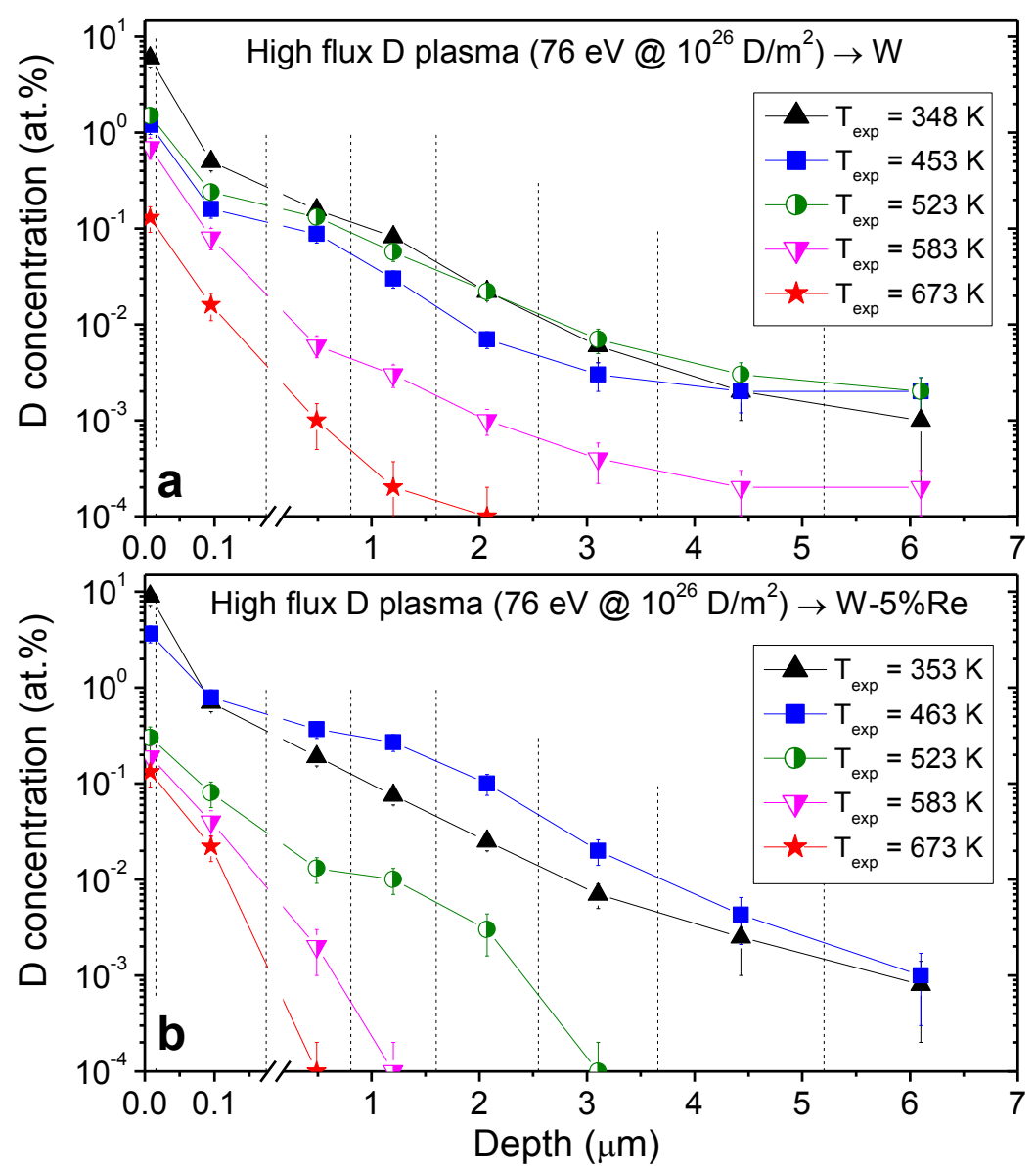

Figure 3. Depth profiles of deuterium retained in warm-rolled $\mathrm{W}$ (a) and $\mathrm{W}-5 \% \operatorname{Re}$ (b) exposed to low-energy, high flux D plasma with an ion fluence of $10^{26} \mathrm{D} / \mathrm{m}^{2}$ at various temperatures. The vertical lines show the nine layers used for the SIMNRA calculations. For each layer, the D concentration is constant across the whole layer width. 

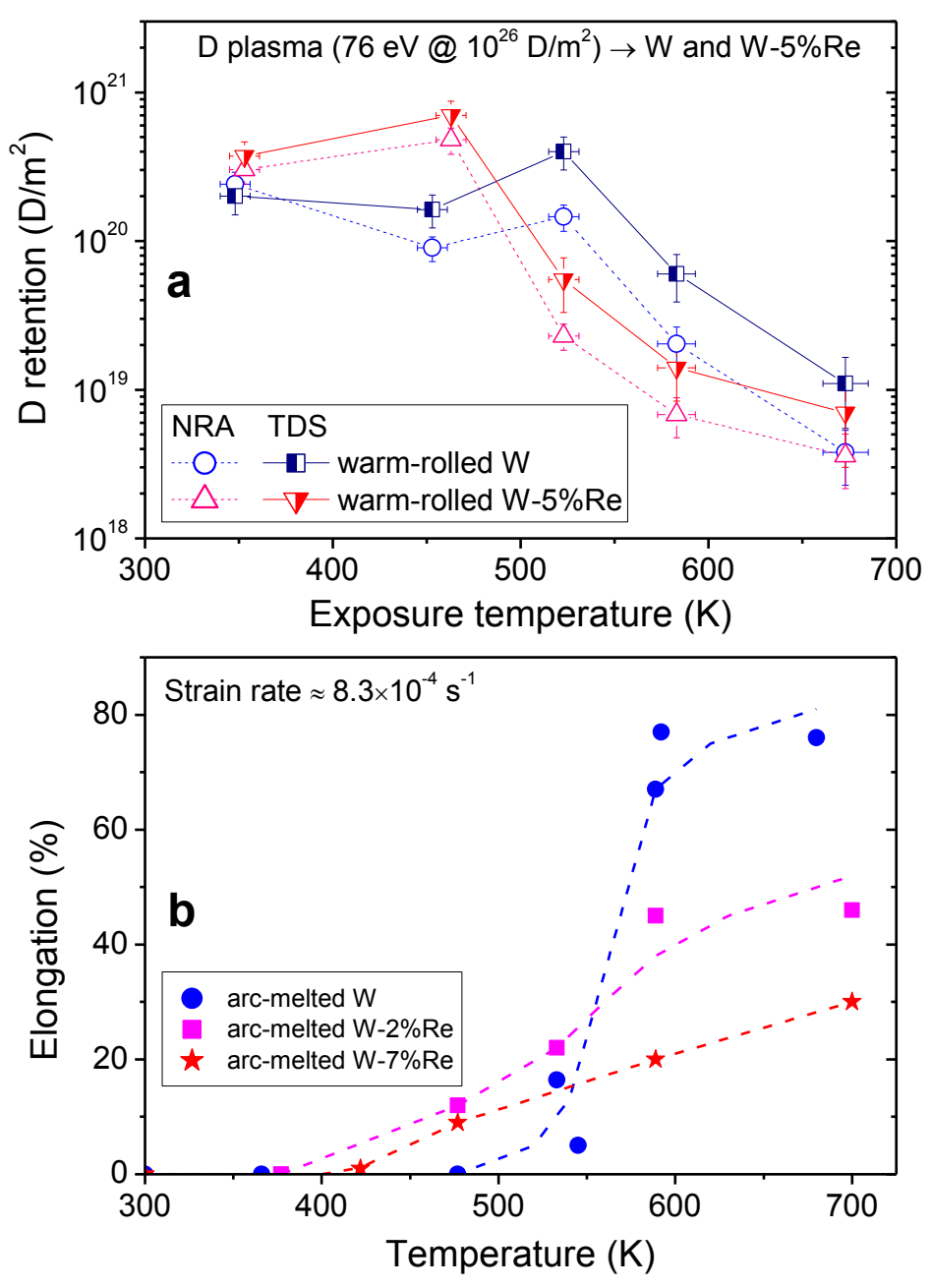

Figure 4. (a) Deuterium retention of warm-rolled W and W-5\%Re exposed to low-energy, high flux D plasma with an ion fluence of $10^{26} \mathrm{D} / \mathrm{m}^{2}$, as a function of the exposure temperature. The total deuterium retention was determined by thermal desorption spectrometry (TDS) (half-filled symbols), whereas the D retention up to a depth of $7 \mu \mathrm{m}$ was measured by nuclear reaction analysis (NRA) (open symbols). (b) Effect of rhenium on ductility of arc-melted tungsten determined by tensile tests at a strain rate of approximately $8 \times 10^{-4} / \mathrm{s}[14]$. 